H.K. Beyer, H.G. Karge, I. Kiricsi and J.B. Nagy (Eds.)

Catalysis by Microporous Materials

Studies in Surface Science and Catalysis, Vol. 94

(C) 1995 Elsevier Science B.V. All rights reserved.

\title{
Zeolite induced chemical selectivity during toluene alkylation
}

\author{
Gabriele Eder-Mirth, Heinz D.Wanzenböck and Johannes A.Lercher
}

Department of Chemical Technology and

Christian Doppler Laboratory for Heterogeneous Catalysis, University of Twente, Postbus 217, 7500 AE Enschede, The Netherlands

The role of the acid base properties of a catalyst to direct the surface chemistry and hence the selectivity in catalyzed reactions, i.e., the toluene methylation with methanol, was investigated. It is shown that the selectivity depends critically upon the nature of the surface complexes and the concentration of the two reactants in the zeolite pores. In the presence of Bronsted acid sites, only xylenes are found as primary products. Methanol is preferentially adsorbed over toluene, the rate of methylation being directly proportional to the surface concentration of chemisorbed methanol. The aromatic ring of toluene is only weakly adsorbed and interacts with the sorbed methanol species. On strong basic zeolites (e.g., $\mathrm{Rb}-\mathrm{X}$ ), toluene is preferentially adsorbed over methanol. Toluene is strongly bound via the aromatic ring to the $\mathrm{Rb}$ cation and the methyl group interacts with the lattice oxygens of the zeolite. At reaction temperatures, methanol forms a formaldehyde like species at the surface. The positively charged carbon-atom of chemisorbed formaldehyde reacts with the carbon atom of the side chain of sorbed toluene to yield styrene as the main product.

\section{INTRODUCTION}

The chemical selectivity obtained in the alkylation of aromatic molecules over zeolitic catalysts critically depends upon their acid base properties. While xylenes are the primary products in the methylation of toluene over acidic zeolites like HZSM5 [e.g. 1,2,3], ethylbenzene and styrene are formed over basic zeolites such as $\mathrm{Rb}-\mathrm{X}$ and $\mathrm{Cs}-\mathrm{X}$ [e.g. 4,5,6]. Previous reports suggested the surface chemistry of chemisorbed methanol to be the most decisive parameter to determine the selectivity $[7,8]$. Recent experiments on toluene methylation to xylenes indicated, however, that various bimolecular precursors to the transition state in the rate determining step exist and may be important for the catalytic properties of zeolites $[9,10]$.

We report an in situ IR spectroscopic study performed during sorption and kinetic measurements to show that these adsorbate structures consequently predetermine the chemical selectivity. The importance of the individual surface species (and their relative concentrations) on the activity and selectivity of the catalyst for the alkylation of aromatic molecules is investigated. 


\section{EXPERIMENTAL}

\subsection{Materials}

The protonic form of zeolite $\mathrm{ZSM}-5\left(\mathrm{H}_{2.6} \mathrm{Al}_{2.6} \mathrm{Si}_{95.4} \mathrm{O}_{196,} \mathrm{Si} / \mathrm{Al}=35\right)$ obtained from MOBIL Corp. and a partially $\mathrm{Rb}$ ion exchanged form of $\mathrm{X}$ faujasite $\left(\mathrm{Rb}_{46} \mathrm{Na}_{24} \mathrm{Al}_{70} \mathrm{Si}_{122} \mathrm{O}_{384}, \mathrm{Si} / \mathrm{Al}=1.75\right)$ obtained from Union Carbide Corp. were used as typical zeolites with an acidic and basic character, respectively.

\subsection{Sorption and coadsorption experiments}

IR spectroscopy was mainly used to characterize the sorbed species. The zeolite powder was pressed into self supporting wafers and analyzed in situ during all treatments (i.e., activation, sorption, reaction) by means of transmission absorption IR spectroscopy using a BRUKER IFS 88 FTIR spectrometer (resolution $4 \mathrm{~cm}^{-1}$ ). For the sorption experiments, an IR cell equipped with IR transparent windows which could be evacuated to pressures below $10^{-6}$ mbar was used [11]. The activated zeolite wafer was contacted with a constant partial pressure $(0.001 \mathrm{mbar})$ of the adsorbate at $308 \mathrm{~K}$ until adsorption-desorption equilibrium was reached (which was monitored by time resolved IR spectroscopy). For the coadsorption experiments, the catalysts were equilibrated with 0.001 mbar of both adsorbates admitted in sequentional order. The spectra were normalized for the sample thickness by comparing the intensities of the absorption bands of the adsorbate with the integral intensity of the lattice vibration bands of the zeolite between 2090 and $1740 \mathrm{~cm}^{-1}$. The surface coverage was quantified by calibration with gravimetric measurements (under conditions identical to the IR spectroscopic experiments).

\subsection{Reaction studies}

For in situ reaction studies, an IR cell which approximates a continuously stirred tank reactor (volume $=1.5 \mathrm{~cm}^{3}$ ), equipped with $1 / 16^{\prime \prime}$ gas in- and outlet tubing and $\mathrm{CaF}_{2}$ windows, was used [12]. For the characterization of the surface species in the zeolite pores during the reaction, time resolved IR spectra of the catalyst were recorded as the activated zeolite was contacted with a He stream containing the reactants. Simultaneously, samples of the effluent gas stream were collected in sample loops of a multi port valve and subsequently analyzed by gas chromatography. This allowed to directly compare the type and concentration of the surface species with the rate of the catalyzed reaction.

\section{RESULTS and DISCUSSION}

\subsection{Sorption and surface reaction of methanol}

The IR spectra of methanol sorbed on (the acidic zeolite) HZSM5 and (the basic zeolite) $\mathrm{Rb}-\mathrm{X}$ show distinct differences in the absorption maxima, the shape and the relative intensities of the $\mathrm{CH}$ and $\mathrm{OH}$ vibrational bands (see Fig. 1). For methanol on HZSM5, $\mathrm{CH}$ stretching vibration bands were observed at $3012,2993,2958$ and $2856 \mathrm{~cm}^{-1}$. OH vibration bands induced by the sorption of methanol were observed at 3545, 2900, $2400\left(v_{\text {stretch }}\right)$ and $1687 \mathrm{~cm}^{-1}\left(v_{\text {def }}\right)$. These bands were attributed to a methoxonium ion hydrogen bound to the lattice of HZSM5 [see refs. 13,14,15,16,]. Gravimetric measurements indicate that under the experimental conditions chosen $(T=308 \mathrm{~K}, \mathrm{p}=0.001 \mathrm{mbar}$ ), all acid sites were covered with one alcohol molecule. With increasing temperature, elimination of water from the protonated surface species of methanol occurred. In parallel to the desorption of water, the formation of methoxy groups associated with the bridging oxygen between the $\mathrm{Al}$ and the neighbouring silica tetrahedron $\left(\mathrm{Si}-\mathrm{OCH}_{3}-\mathrm{Al}\right)$ of the 
negatively charged lattice of HZSM5 takes place $[16,17,18]$.

With $\mathrm{Rb}-\mathrm{X}$, the bands attributed to the $\mathrm{CH}$ stretching vibrations of sorbed methanol were observed at much lower wavenumbers (2936 and $2820 \mathrm{~cm}^{-1}$ ) compared to methanol adsorbed on HZSM5 suggesting strong interaction of the methyl group with the zeolite. At a partial pressure of 0.001 mbar, a coverage of 0.5 methanol molecules per cation was achieved. The hydroxyl group of methanol sorbed on $\mathrm{Rb}-\mathrm{X}$ gave rise to a broad band centred around $3236 \mathrm{~cm}^{-1}$ (width at half height $=310 \mathrm{~cm}^{-1}$ ) Upon sorption of methanol on $\mathrm{Na}-\mathrm{X}$, the corresponding OH-band was observed at $3353 \mathrm{~cm}^{-1}$ (width at half height $=300 \mathrm{~cm}^{-1}$ ), on Na-ZSM5 at $3613 \mathrm{~cm}^{-1}$ (width at half height $=55 \mathrm{~cm}^{-1}$ ). It should be noted that the band of the $v_{\text {stretch }}$ of a free OH group of methanol is sharp and has a maximum at approximately $3680 \mathrm{~cm}^{-1}$. The much lower wavenumber and the width of the band observed for methanol on $\mathrm{Rb}-\mathrm{X}$ indicates, therefore, strong hydrogen bonding of the hydroxyl group to the zeolite lattice. Thus, we propose that methanol is coordinatively bound via the lone electron pair of its oxygen to the cation in zeolite Rb-X. Simultaneously, strong interactions of the proton of the hydroxyl group with the basic lattice oxygens of $\mathrm{Rb}-\mathrm{X}$ occur. At elevated temperatures, a $\mathrm{H}_{2}$ molecule is split off resulting in the formation of formate species at the surface $[7,8]$. The probability of the formation of methoxy species is decreasing with increasing size of the alkali cation of the zeolite and is expected to be very low for $\mathrm{Rb}-\mathrm{X}$. The reaction of methanol on basic zeolites ( $\mathrm{Rb}-\mathrm{X}$ and $\mathrm{Cs}-\mathrm{X}$ ) at $673 \mathrm{~K}$ yields adsorbed formaldehyde and formate species, which are absent on acidic zeolites like HZSM5 or even at the less basic Na-X [see also $7,8]$.

\section{Absorbance [a.u.]}

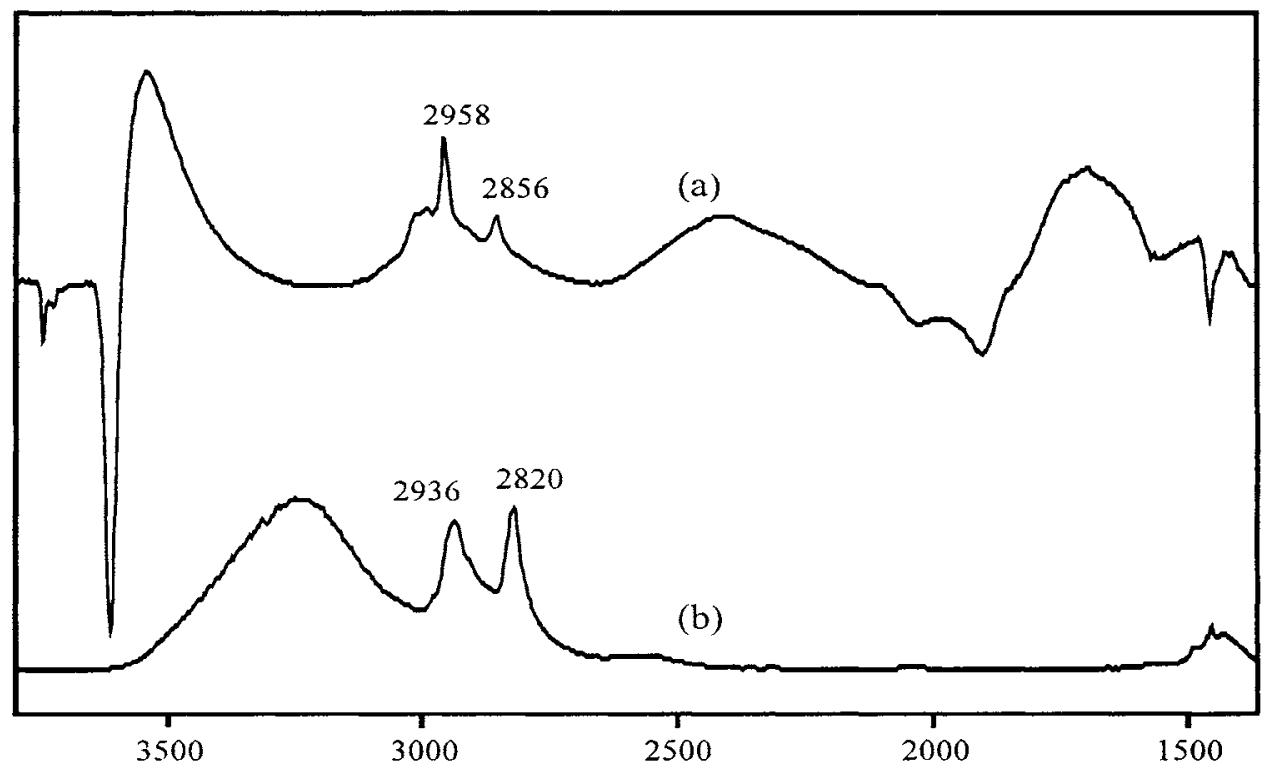

Wavenumbers $[\mathrm{cm}-1]$

Figure 1. IR spectra of methanol sorbed on (a) HZSM5 and (b) Rb-X (T=308 K, p= $0.001 \mathrm{mbar}$ ) 


\subsection{Sorption of toluene}

Similarly, toluene was found to be quite differently sorbed on the two zeolites investigated. The most striking differences were seen in the IR spectra of the sorbed species in the region of the $\mathrm{CH}$ stretching vibrations (see Fig.2). In both cases, the coverage of toluene per sorption site (Si$\mathrm{OH}-\mathrm{Al}$, alkali cation) was lower than for methanol under otherwise identical conditions $(0.5$ toluene/site in HZSM5 and 0.25 toluene/cation in Rb-X at $\mathrm{p}_{\text {toluene }}=0.001 \mathrm{mbar}$ ).

The shift (from 3610 to $3220 \mathrm{~cm}^{-1}$ ) and the broadening of the Si-OH-Al band of the zeolite after sorption of toluene on HZSM5 (Fig. 2a) indicates hydrogen bonding of the aromatic molecule on the hydroxyl group. Because the absorption maxima and the relative intensities of the bands of the $\mathrm{CH}$ stretching vibrations of toluene on HZSM5 were similar to those of toluene on amorphous silica, only weak interactions between the hydrogen atoms of toluene and the zeolite lattice were concluded to exist.

After sorption of toluene on $\mathrm{Rb}-\mathrm{X}$, the bands attributed to the asymmetric and symmetric $\mathrm{CH}_{3}$-stretching vibrations were observed at 12 and $20 \mathrm{~cm}^{-1}$ lower wavenumbers than after sorption of toluene on HZSM5. This is interpreted as a weakening of the $\mathrm{C}-\mathrm{H}$ bonds due to strong interactions of the methyl group with the lattice oxygens of $\mathrm{Rb}-\mathrm{X}$.

\section{Absorbance [a.u.]}

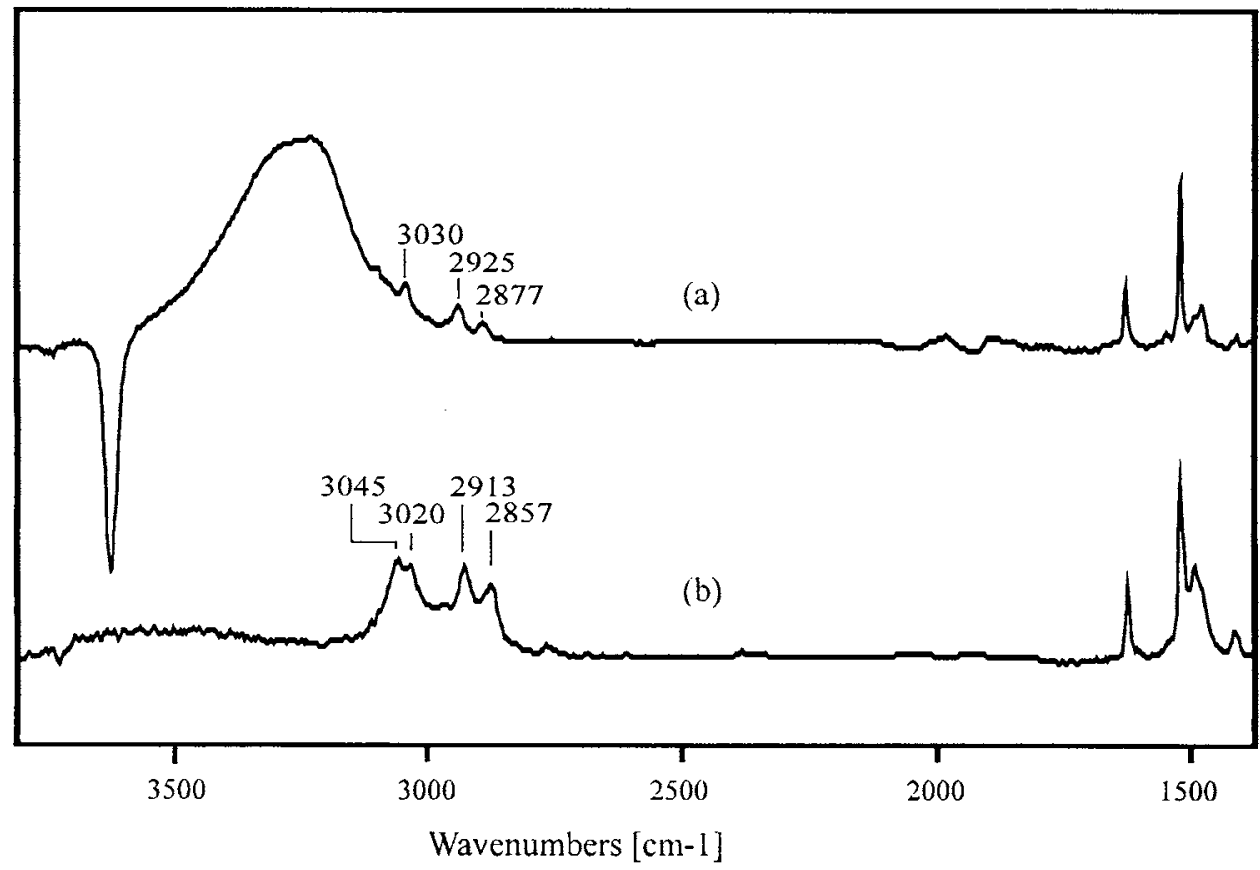

Figure 2. IR spectra of sorbed toluene on (a) HZSM5 and (b) Rb-X (T=308 K, p=0.001 mbar)

In general, the interaction between toluene and $\mathrm{Rb}-\mathrm{X}$ is much stronger than the interaction between toluene and the Brönsted acidic HZSM5. This results mainly from 2 contributions: (i) The large cations in $\mathrm{Rb}-\mathrm{X}$ are much better suited to symmetrically interact with the aromatic ring of 
toluene than the small protons in HZSM5. (ii) The hydrogen atoms of toluene seem to strongly interact with the oxygens of the lattice of $\mathrm{Rb}-\mathrm{X}$ leading to multi point interaction [19]. In consequence this situation leads to the low mobility of the sorbed molecules which was also concluded from NMR studies $[20,21]$. It is suggested that the strong interaction of toluene with the zeolite leads to a configuration were the delocalized $\pi$ electrons of the ring are forced in localized double bonds resulting in a $\mathrm{C}_{6} \mathrm{H}_{6}=\mathrm{CH}_{2}$ like structure [22]. In this case, the side chain of toluene is strongly polarized and will interact with the positively polarized $\mathrm{C}$-atom of the methylating species (formaldehyde) to yield side chain alkylated products.

\subsection{Coadsorption and reaction of toluene and methanol}

Coadsorption of both reactants on HZSM5 resulted in a spectrum in which the $\mathrm{OH}$ band typical for the hydrogen bonding between toluene and the zeolite $\left(3220 \mathrm{~cm}^{-1}\right)$ was absent. The intensities of the bands of the $\mathrm{OH}$ vibrations of adsorbed methanol were lower compared to single adsorption of methanol alone while those of the $\mathrm{CH}$ vibrations were similar. These effects in combination with the appearance of a new IR band at $3460 \mathrm{~cm}^{-1}$ which was not observed after sorption of either one of the reactants alone indicates that a bimolecular complex between methanol and toluene at the acid sites of HZSM5 is formed [10]. In this complex, methanol is directly sorbed at the Si-OH-Al group of the zeolite. The band at $3460 \mathrm{~cm}^{-1}$ was attributed to the $\mathrm{OH}$ stretching vibration of chemisorbed methanol interacting with the aromatic ring of toluene [9]. While all active sites were covered with methanol, less than half of these molecules form a coadsorption complex with toluene under the experimental conditions $(T=308 \mathrm{~K}, \mathrm{p}=0.001$ mbar of each reactant).

It should be stressed that a preferential adsorption of methanol over toluene occurs not only on Brönsted acidic zeolites like HZSM5, but was also observed upon coadsorption of methanol and toluene on $\mathrm{Na}-\mathrm{X}$. In this case, methanol was present in 4 fold excess over toluene.

Upon heating, the loaded HZSM5 catalyst in a gas stream containing both reactants, the coadsorption complex was observed up to temperatures of $453 \mathrm{~K}$. The decrease in its concentration occurred in parallel with the appearance of the first reaction products (xylenes)(see Figure 3). Thus, we concluded that it is likely to be a possible precursor to the transition state in the methylation reaction. This is supported by the fact that under reaction conditions the rate of methylation of toluene was found to be directly proportional to the surface concentration of the activated methanol species $[23,10]$. We think that during the reaction only a small concentration of the bimolecular complex exists which can not be monitored by IR spectroscopy. Its abundance should, however, depend upon the concentration of chemisorbed methanol.

When both reactants were coadsorbed on $\mathrm{Rb}-\mathrm{X}$ at $308 \mathrm{~K}$, indications for the formation of reaction products or bimolecular complexes were not found in the IR spectra. The spectra rather suggest that toluene and methanol are independently sorbed. It should be noted, however, that after equilibration with equal partial pressures of both reactants, toluene was the main sorbed species. Note that only part of the sites can be covered by toluene molecules due to steric reasons (theoretically $2 / 3$ of the cations are accessible) and pore filling, while methanol achieved a coverage of approximately one molecule/cation at elevated partial pressures $(p=1 \mathrm{mbar})$. Coadsorption of toluene onto a surface preequilibrated with methanol resulted in the displacement of the main fraction of the methanol molecules $(80 \%)$ from the sorption sites [24]. The same coadsorbed state was reached irrespective of the sequence of adsorption of the two reactants. If toluene was adsorbed first, coadsorption of methanol did not change the coverage of toluene.

Toluene was observed to be the main adsorptive on the $\mathrm{Rb}-\mathrm{X}$ also under reaction 
conditions. Even at elevated temperatures (measurable conversions were not achieved below 623 $\mathrm{K})$ toluene was strongly bound with the aromatic ring to the cation while the methyl group was interacting with the lattice oxygens of the zeolite. Although toluene was preferentially adsorbed over methanol which formed chemisorbed formaldehyde at this temperature, a direct correlation between the rate of methylation and the surface concentration of both reactants was observed. Styrene is suggested to be the only primary product formed by the reaction of toluene with formaldehyde which is subsequently hydrogenated in part to ethylbenzene[25].

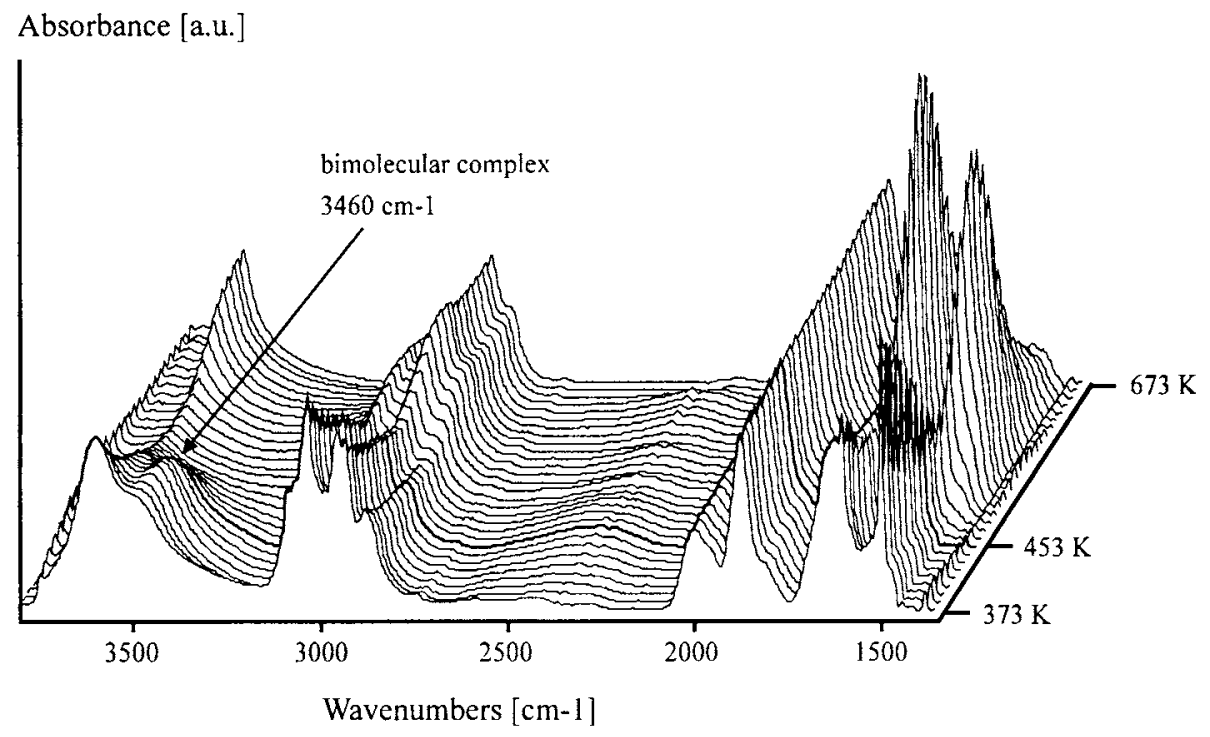

Figure 3. IR spectra of HZSM5 during the reaction of toluene and methanol as function of the reaction temperature $(T=373-673 \mathrm{~K})$

\section{CONCLUSIONS}

In situ IR studies of sorbed toluene and methanol under non reactive conditions showed that both reactants assume different adsorption structures on HZSM5 and Rb-X. While methanol is stabilized as hydrogen bonded methoxonium ion in the pores of HZSM5, it is coordinatively bound via its oxygen to the cations in zeolite $\mathrm{Rb}-\mathrm{X}$. In addition to this coordinative bond, strong lateral interactions of the hydroxyl group of methanol with the basic oxygens of the lattice of zeolite $\mathrm{Rb}-\mathrm{X}$ were detected.

Toluene adsorbed on $\mathrm{Rb}-\mathrm{X}$ is strongly interacting with the cation and the framework oxygen atoms. By comparison with the IR spectra of toluene hydrogen bonded to the $\mathrm{OH}$ groups of silica or protonic zeolites like HZSM5, it can be concluded that the $\mathrm{C}-\mathrm{H}$ bonds of the methyl group of toluene are significantly weakened. This makes the methyl group the preferential site for an attack of the surface bound formaldehyde species.

In the case of HZSM5, the elimination of water from chemisorbed methanol becomes favourable with increasing temperature leading to the formation of a methoxy group associated with the negatively charged lattice $\left(\mathrm{Si}-\mathrm{OCH}_{3}-\mathrm{Al}\right.$ ). In contrast, the abstraction of hydrogen from methanol adsorbed on the basic zeolite $\mathrm{Rb}-\mathrm{X}$ led to the formation of chemisorbed formaldehyde 
and formate.

Coadsorption of both reactants resulted in the formation of a bimolecular complex between methanol and toluene at the acid sites of HZSM5. This complex involves the interaction of the protonated hydroxyl group of a methoxonium ion with the aromatic ring of toluene. Methanol is preferentially adsorbed over toluene on acidic zeolites. Under the reaction conditions employed, the rate of methylation of toluene was found to be directly proportional to the surface concentration of the activated methanol species. The concentration of the bimolecular complex, which is expected to be a precursor to the transition state in the rate determining step is very low under reaction conditions.

In contrast, toluene and methanol coadsorbed on $\mathrm{Rb}-\mathrm{X}$ do not form a bimolecular precursor complex and both reactants seem to be independently adsorbed at the surface. It should be noted, however, that after equilibration of the catalyst with equal partial pressures of both reactants, toluene was the main adsorptive. During toluene methylation, sorbed toluene was again the main surface species, the reaction rate, however, was proportional to the surface concentrations of both chemisorbed species (toluene, formaldehyde). The onset of the reaction was observed at much higher temperatures than in the ring alkylation which is at large ascribed to the indispensable conversion of methanol to a formaldehyde (or formate) species.

\section{REFERENCES}

1. N.Y. Chen, W.W. Kaeding, and T. Dwyer, J.Am.Chem.Soc. 101 (1979) 6783.

2. W.W. Kaeding, C.Chu, L.B. Young and S.A. Butter, J.Catal. 67 (1981) 159.

3. L.B.Young, S.A. Butter and W.W. Kaeding, J.Catal. 76 (1982) 418.

4. T.Yashima, K. Sato, T. Hayasaka and N. Hara, J.Catal. 26 (1972) 303.

5. Y.N. Sidorenko, P.N. Galich, V.S. Gutyrya, V.G. Ilin and I.E. Neimark, Dokl.Akad. Nauk.SSSR, 173 (1967) 132.

6. J. Engelhardt, J. Szanyi and J.Valyon, J.Catal. 107 (1987) 296.

7. M.L. Unland, J.Phys.Chem. 82 (1978) 580.

8. S.T. King and J.M.Garces, J.Catal. 104 (1987) 59.

9. G. Mirth and J.A.Lercher, J.Phys. Chem. 95 (1990) 3736.

10. J. Rakoczy, React. Kinet Catal.Lett. 48 (2) (1992) 401

11. A. Jentys, G. Warecka and J.A. Lercher, J.Mol.Catal. 51 (1989) 309.

12. G. Mirth, F. Eder and J.A. Lercher, Appl.Spectroscopy 48 (2)(1994) 194.

13. G. Mirth, J.A. Lercher, M.W. Anderson and J. Klinowski, J.Chem.Soc.Farad. Trans. 86 (17) (1990) 3039 .

14. G. Mirth, A. Kogelbauer and J.A. Lercher, Butterworth-Heinemann, Eds. R.van Ballmoos et al., Proc. 9th IZC, Montreal (1992), 251.

15. M.T. Aronson. R.J. Gorte and W.E. Farneth, J.Catal.98 (1986) 434 and Langmuir 4 (1988) 702.

16. L. Kubelkova, J. Novakova and K. Nedomova, J.Catal. 124 (1990) 441

17. T.R. Forester and R.F. Howe, J.Am.Chem.Soc. 109 (1987) 5076.

18. J. Novahova, L. Kubelkova and Z. Dolejsek, J.Catal., 108 (1987) 208.

19. J.A.Freeman and M.L. Unland, J.Catal. 54 (1978) 183.

20. M.D. Sefcik, J.Am.Chem.Soc. $101(8)$ (1979) 2164.

21. V.Y. Borovkov, W.K. Hall and V.B. Kazanski, J.Catal. 51 (1978) 437.

22. G. van Koten, private communication.

23. G. Mirth, J. Cejka and J.A. Lercher, Stud.Surf.Sci.Catal. 83 (1994) 287.

24. H. Wanzenböck. Diploma thesis, Technical University of Vienna (1994).

25. Y.N. Sidorenko and P.N. Galich, Dokl.Akad.Nauk.SSSR 174 (1968) 1234. 